\title{
Figures, tables and boxes
}

\section{FIGURES}

1.1 Growth and components of Australia's population change, 1986-2007

1.2 Settler arrivals in Australia by eligibility category, 1986-2007 6

2.1 Australia: settler arrivals by state, according to whether or not they are SSRM scheme migrants, 2006-07

2.2 Australia: temporary migration by category, 1986-2007 31

2.3 Australia: settler arrivals by region of last residence, 1947-2006 34

2.4 Australia: permanent and long-term departures of residents, 1959-60 to 2007-08

3.1 US: unauthorized stocks and flows of population, 1980-2008 50

3.2 Immigrant and temporary non-immigrant employment visas issued by the US State Department, 1988-2007 52

7.1 US: dropout rates of first- and second-generation men $\quad 108$

\section{TABLES}

1.1 Approximate annual immigration to the US, 2002-06

4.1 Restrictive immigration proposals in the US Congress that died, were defeated or were weakened by amendment, 1995-2001

5.1 Migration programme outcomes, 2000-01 to 2006-07 and planned, 2007-08

\section{BOXES}

4.1 Main provisions of IIRIRA, 1996

8.1 Dr Peter Shergold, Foundation Director, Office of Multicultural Affairs, 1987-90

8.2 Professor Stephen FitzGerald Chair, Committee to Advise on Australia's Immigration Policies (CAAIP), 1987-88 